\title{
Prognostic value of TGF- $\beta$ in lung cancer: systematic review and meta-analysis
}

\author{
Jue Li ${ }^{\dagger}$, Cheng Shen ${ }^{\dagger}$, Xin Wang, Yutian Lai, Kun Zhou, Pengfei Li, Lunxu Liu and Guowei Che*
}

\begin{abstract}
Background: Lung cancer is the most important cause of cancer-related deaths worldwide and the overall survival of patients with non-small cell lung cancer has not improved. Transforming growth factor beta or TGF- $\beta$ is a polypeptide member of the transforming growth factor beta superfamily of cytokines, while far fewer clinical studies addressing the association between TGF- $\beta$ expression and the disease prognosis have been reported up to now. Therefore, our meta-analysis aims to determine the prognostic significance of TGF- $\beta$ expression in lung cancer patients.

Methods: PubMed, EMBASE, the Web of Science and China National Knowledge Infrastructure (CNKI) databases were searched for full-text literature citations. We applied the hazard ratio (HR) with 95\% confidence interval (CI) as the appropriate summarized statistics. Q-test and $I^{2}$ statistic were used to estimate the level of heterogeneity. The publication bias was detected by Begg's test and Egger's test.

Results: Eight eligible studies involving 579 patients were selected for this meta-analysis. The combined HR for the eight eligible studies was 2.17 (95\% Cl: 1.71-2.77, $P<0.00001)$ and heterogeneity of overall prognosis was relatively low $\left(I^{2}=14.2 \%, P=0.319\right)$. We further undertook the subgroup analysis including assessment of the association between TGF- $\beta$ expression and pathology of the lung cancer, treatment and quantity of sample in studies. All the results revealed that a significantly high TGF- $\beta$ expression in patients was an indicator of poor survival. Neither Begg's test nor Egger's test found publication bias in any analysis.
\end{abstract}

Conclusions: The present evidence indicates that TGF- $\beta$ expression can significantly predict the worse prognosis in patients with lung cancer. The findings of our meta-analysis may be confirmed in the future by the use of more updated review pooling and additional relevant investigations.

Keywords: TGF- $\beta$, Lung cancer, Prognosis, Meta-analysis

\section{Background}

Lung cancer is the most common malignant tumor in the world [1]. It is still difficult to improve the overall survival of patients with non-small cell lung cancer (NSCLC) and the most patients their treatment is limited to chemotherapy or radiotherapy. Further, a simple and effective tool for predicting therapeutic efficacy and prognosticating the disease of the patients with lung cancer is lacking $[2,3]$. With the development of targeted therapy research and the popularity of clinical application, many concerned researchers

\footnotetext{
*Correspondence: cheguowei_hx@aliyun.com

†Jue Li and Cheng Shen contributed equally to this work.

Department of Thoracic Surgery, West-China Hospital, Sichuan University, Chengdu 610041, China
}

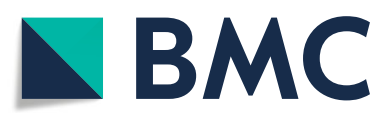

(c) The Author(s). 2019 Open Access This article is distributed under the terms of the Creative Commons Attribution 4.0 International License (http://creativecommons.org/licenses/by/4.0/), which permits unrestricted use, distribution, and reproduction in any medium, provided you give appropriate credit to the original author(s) and the source, provide a link to the Creative Commons license, and indicate if changes were made. The Creative Commons Public Domain Dedication waiver (http://creativecommons.org/publicdomain/zero/1.0/) applies to the data made available in this article, unless otherwise stated. prognostic factors for lung cancer targeted therapy.

Transforming growth factor beta (TGF- $\beta$ ) is a member of a multifunctional cytokine family that regulates cell proliferation $[4,5]$. It appears to play a dual role in cancer. TGF- $\beta$ signaling that acts as a tumor suppressor inhibits cell proliferation in normal epithelial cells and hematopoietic cells [5-8]. Studies have shown that many tumors evade immune system recognition by increasing the expression of TGF- $\beta$ in the environment, thereby increasing the risk of tumor recurrence and metastasis [9]. However, fewer studies have examined the association between TGF- $\beta$ expression and prognosis of patients with lung cancer. At the same time, research has shown that high TGF- $\beta$ expression predicts poor prognosis in 


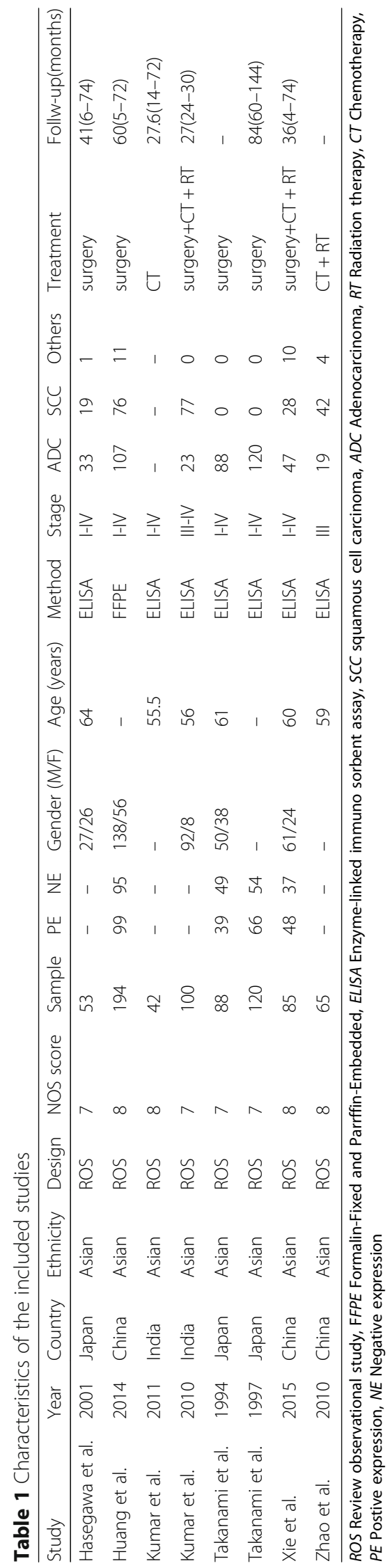


patients with liver cancer [10]. Therefore, we performed this meta-analysis to assess the prognostic value of TGF$\beta$ in patients with NSCLC.

\section{Method}

\section{Searching strategies}

All of the research was published from June 1993 to July 2018 in the Pubmed, Web of Science, EMBASE and CNKI databases. The key words used are as follows:(I) "TGF- $\beta$ or TGF-beta"; (II) "Pulmonary Neoplasms or Lung Cancer"; (III) "Prognoses or Prognostic Factors". Additionally, to avoid duplication of data from different publications from the same author or research team, we further studied these articles to ensure that there was no duplication of research.

\section{Inclusion and exclusion criteria}

Inclusion criteria: (I) Lung cancer is the main research object; (II) Demographic data or survival curves can be obtained in original studies. (III) All the study published with full texts.

Exclusion criteria: (I) The type of article that does not include a review, case report, letter and meeting report.(II) Non-human subject studies. (III) The HR value could not be obtained from the provided data.

\section{Quality assessment}

The guideline of Newcastle-Ottawa Scale (NOS) was used for evaluating this research including three perspectives of selection, comparability and exposure. The assessment tool including the star system, a maximum of 9 stars, was used in this research. Specific evaluation system is that 8-9 stars are high quality; 6-7 stars are reasonable quality, and 6 stars or less are bad. (Table 1).

\section{Data collection}

Two reviewers (Shen and Li) collected data from each study. Any unclear or inconsistent issues are dealt with through discussion. Excel is used to collect the following information (Table 1): author, publication year, country, study design, study period, detection method, follow-up time, included samples, age, gender, tumor staging, tumor histology, number of patients, TGF- beta expression, treatment information and survival analysis.

\section{Statistical analysis}

The Stata 14.2 software was used to analyze the statistical data and the Engauge Digitizer 10.0 software was used to extract the survival data from the Kaplan-Meier survival curves. This study used Q test and i2 statistics to estimate

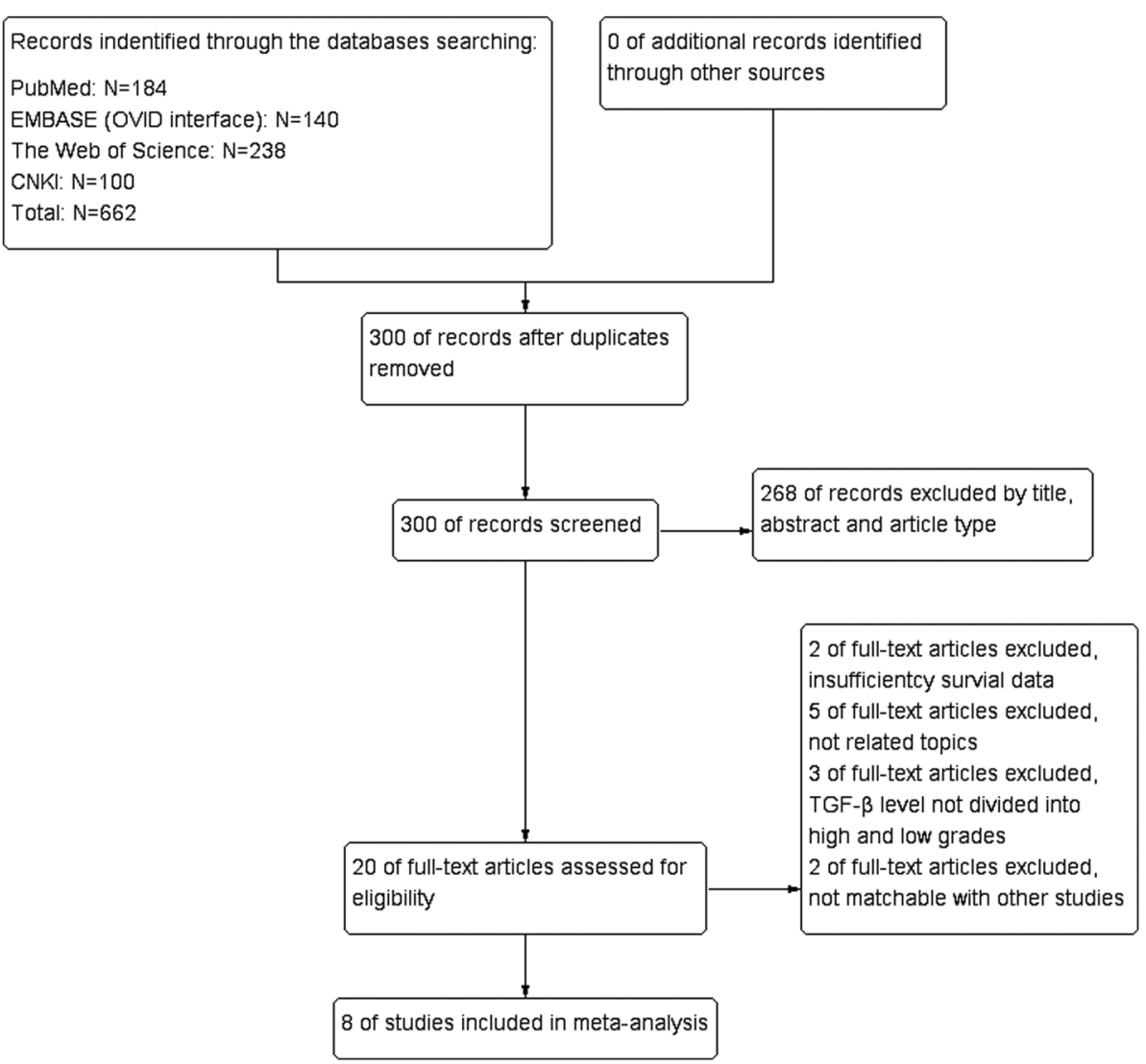

Fig. 1 Flow chart of study selection in this meta-analysis 
the level of heterogeneity. According to the heterogeneity of $\mathrm{I}^{2}<50 \%$ or $\mathrm{I}^{2} \geq 50 \%$, a fixed effect model test or a random effect model test is selected. HR $>1$ implies the poor prognosis for high TGF- $\beta$ level, and $\mathrm{P}<0.05$ was statistically significant. The Begg's funnel plot analysis used to evaluate the publication bias, and the source of heterogeneity and stability of the results can be accessed by sensitivity analysis and subgroup analysis.

\section{Results}

\section{The selection of included studies}

We searched four electronic databases including PubMed, EMBASE, Web of Science and CNKI and total number of citation is 588. There were 28 articles included by screening of titles and abstracts and excluding duplicate literature entries. Later, there were 268 papers excluded due to unqualified document types, the full text of the remaining documents was read fully. In our meta-analysis, 20 potential qualified papers were identified. Ultimately, only eight articles were involved in the present study [4, 8, 9, 11-16] (Fig. 1).

\section{The characteristics of included studies}

The basic characteristics of eight qualified literature sources are recorded in Table 1 . Takanami et al. [8, 9] focused on TGF- $\beta$ expression in pulmonary adenocarcinomas. Hasegawa et al. [15] enrolled a total of 53 NSCLC tissue samples (19 squamous cell carcinomas, 33 adenocarcinomas, and 1 adenosquamous cell carcinoma) in their study. Kumar et al. [17] estimated diagnosed and untreated Indian lung cancer patients with advanced-stage NSCLC. All of the patients were confirmed by the histological examinations during fibreoptic bronchoscopy or with a computed tomography $(\mathrm{CT})$ - guided procedure. The aim of the study was analyzing the efficacy of plasma TGF- $\beta$ levels as a prognostic factor for survival in patients with chemotherapy. Zhao et al. [16] reported TGF- $\beta$ expression in patients with stage IIIA or IIIB NSCLC treated with radiotherapy. The study of Huang et al. [10] explored the expression intensity and prognostic significance of TGF- $\beta$ in NSCLC patients with immunohistochemistry outcomes. Xie et al. [4] reported the

Study

ID

$\operatorname{hr}(95 \% \mathrm{Cl})$

Hasegawa (2001)

Huang (2014)

Kuamr (2010)

Kumar (2011)

Takanami (1994)

Takanami (1997)

Xie (2015)

Zhao (2010)

Overall $(I-$ squared $=14.2 \%, p=0.319)$

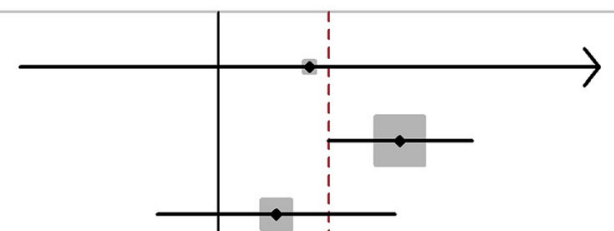

$1.90(0.25,14.50)$

$3.58(2.16,5.93)$

$1.50(0.65,3.46)$

$2.83(1.20,6.66)$

$1.79(0.94,3.41)$

$2.59(1.33,5.04)$

$1.40(0.82,2.39)$

$2.05(1.03,4.08)$

$2.17(1.71,2.77)$

Fig. 2 Forest plots of the eight evaluable studies assessing the prognostic value of TGF- $\beta$ in lung cancer. Cl Confidence intervals, HR Hazard ratio 
prognostic values of TGF- $\beta$ in lung cancer patients in China.

\section{Meta-analysis results}

The combined HR for the eight appropriate studies was 2.17 (95\% CI: 1.71-2.77, $P<0.00001$ ), suggesting that TGF- $\beta$ overexpression was an indicator of poor survival for NSCLC patients (Fig. 2). Heterogeneity of overall prognosis was relatively low ( $\mathrm{I} 2=14.2 \%, P=0.319)$. We further commenced the subgroup investigation.

\section{Valuation of the link between TGF- $\beta$ expression and pathology of the lung cancer}

There were two studies reporting lung adenocarcinoma of patients and the defined HR based on this study was 2.14 (95\% CI: 1.35-3.40) (Fig. 3). The fixed-effect model was then considered for this part $\left(\mathrm{I}^{2}=0.0 \%, P=0.434\right)$. Another two studies that did not define the tumor pathology showed that TGF- $\beta$ overexpression might be a strong predictor of poor survival for NSCLC patients $(\mathrm{HR}=2.04,95 \%$ CI: 1.12-3.72) (Fig. 3). From four of the included studies patients with other pathologies of lung cancer indicated that high TGF- $\beta$ expression was a marker of poor survival ( $\mathrm{HR}=2.23,95 \% \mathrm{CI}: 1.62-3.07$ ) (Fig. 3).

\section{Valuation of the link between TGF- $\beta$ expression and treatment}

We measured the association between TGF- $\beta$ expression and treatment. The samples were treated only with surgery in four studies, the summarized HR of analysis was 2.68 (95\% CI: 1.91-3.75) (Fig. 4). When we compared the relationship between TGF- $\beta$ expression and combination therapy, it was statistically meaningful statistics ( $\mathrm{HR}=1.75 ; 95 \% \mathrm{CI}$ : $1.24-2.46)$. These two findings showed that excessive TGF- $\beta$ expression was a sign of poor survival.

\section{Valuation of the link between TGF- $\beta$ expression and quantity of sample in studies}

On the one hand, with the sample greater or equal to 100, the HR was 3.11 (95\% CI: 0.77-1.50) (Fig. 5). On the other hand, with the sample less than 100, the HR based on analysis also revealed the meaningfully high TGF- $\beta$ expression in patients was an indicator of poor survival (HR: 1.65; 95\% CI: 1.19-2.27) (Fig. 5).

\section{Publication bias}

Both the Begg's funnel plot and Egger's test were completed to assess the publication bias in the literature (Figs. 6 and 7). All eight qualified studies in the literature are available generated a Begg's test score of $P=0.902$

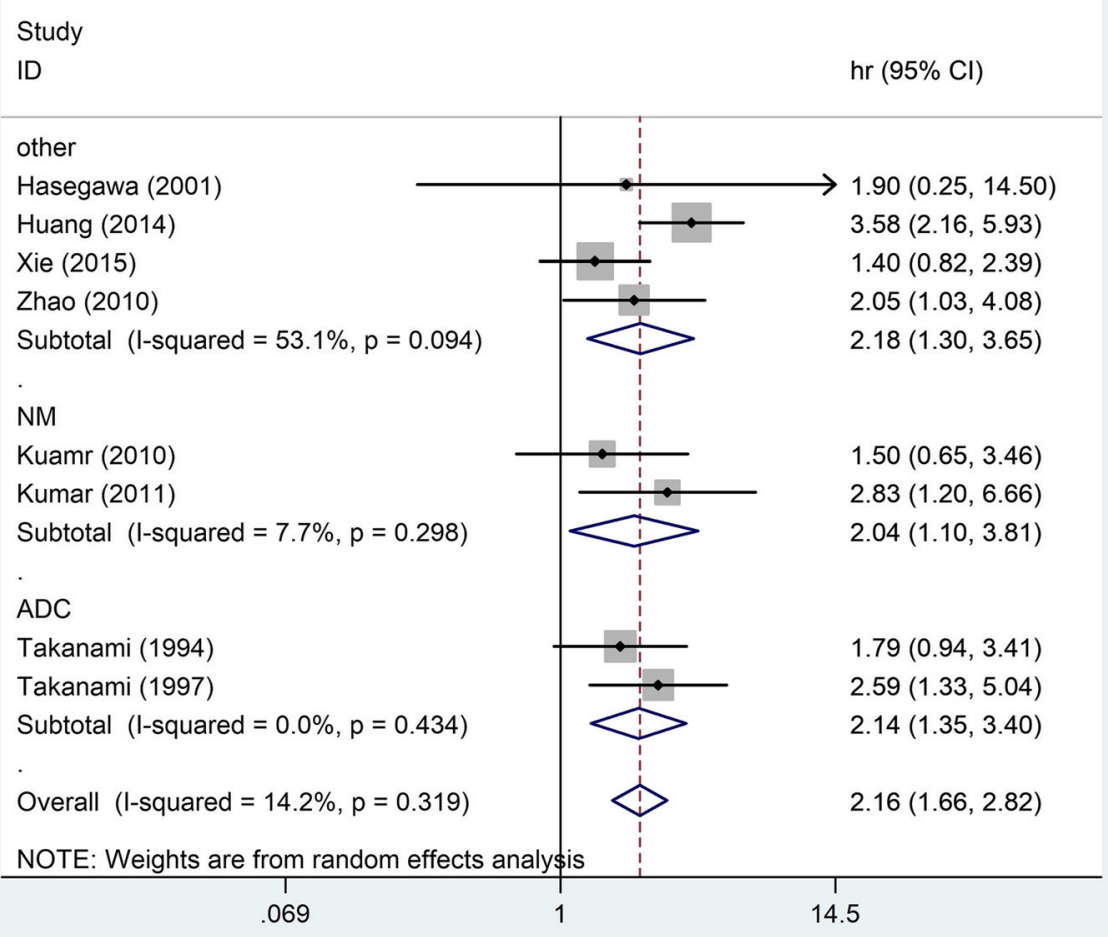

Fig. 3 Pooled HRs for assessing of the association between TGF- $\beta$ expression and pathology of the lung cancer. HR, hazard ratio, Cl Confidence interval, ADC Adenocarcinoma, NM Not mentioned, ES Effect size 


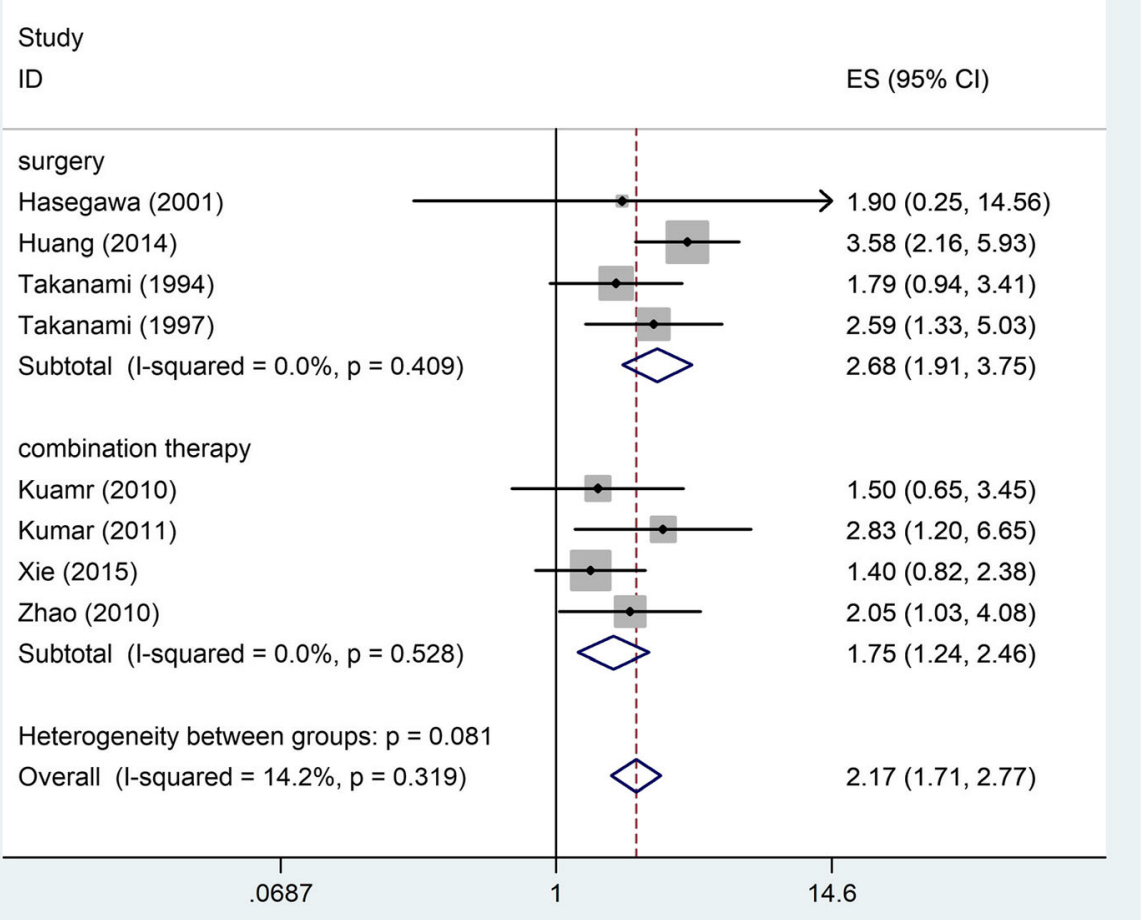

Fig. 4 Pooled HRs for assessing of the association between TGF- $\beta$ expression and treatment. HR Hazard ratio, Cl Confidence interval, ES Effect size

and Egger's test score of $P=0.747$. According to the Begg's tests result, there was no meaning publication bias detected in overall survival. Nonparametric pruning and filling methods were used to assess the impact of this bias and summary HR on overall survival and there was no meaningful publication bias in the study and the combined HR remained significant. In short, the outcomes in our research are statistically dependable.

\section{Discussion}

To our best knowledge, this meta-analysis is the first meta-analysis to evaluate the prognostic value of TGF- $\beta$ expression in patients with NSCLC, although only eight qualified literatures are available at present.

In several studies, TGF- $\beta$ protein expression in patients with NSCLC has been described to correlate with survival $[1,13,14,18]$. TGF- $\beta$ appears to be involved in the tumorigenesis of the patients in these studies. The higher the expression of TGF- $\beta$ protein, the more advanced tumor stage for the patients [12, 18, 19]. In addition, patients appear to be more likely to be diagnosed with lymph node metastasis if the TGF- $\beta$ protein expression was higher than normal levels $[5,20]$.

Some studies indicate that the matrix formed by TGF- $\beta$ may provide a good environment for the tumor growth, and this is a key role in the occurrence and development of cancers [5]. Fibroblasts and mononuclear cells surrounding tumor cells will contribute and produce TGF- $\beta$ at the same time. It is well known that TGF- $\beta$ is one of the growth factors that regulate the composition of the extracellular matrix of the alveolar epithelium and induce epithelial to mesenchymal transition (EMT). The feature including a top surface and a basal plane is described as the "polarity" of epithelial cells. The arrangement between epithelial cells prevents them from detaching from the tissue. Epithelial cells progressively lose cell polarity and adhesions, gain invasive and migratory ability, and produce extracellular matrix components with the influence of some factors during EMT [21-23]. During EMT, cancer cells lose cell-cell adhesion junctions and change into fibroblast-like morphology, resulting in superior mobility and invasiveness $[24,25]$. TGF- $\beta$ expression may promote the growth and differentiation of tumor cells through autocrine or paracrine activity, ultimately resulting in increased cell matrix interaction, inhibition of immune surveillance, or increased angiogenic activity [26]. TGF- $\beta$ can inhibit the growth of normal epithelial cells, but tumor cells have strong resistance to TGF- $\beta$ inhibition. Detection of TGF- $\beta$ gene, mRNA and protein in lung cancer cell lines indicated that tumor cells have a strong proliferative response to TGF- $\beta[27,28]$. Previous studies have observed a strong correlation between the increased TGF- $\beta$ 


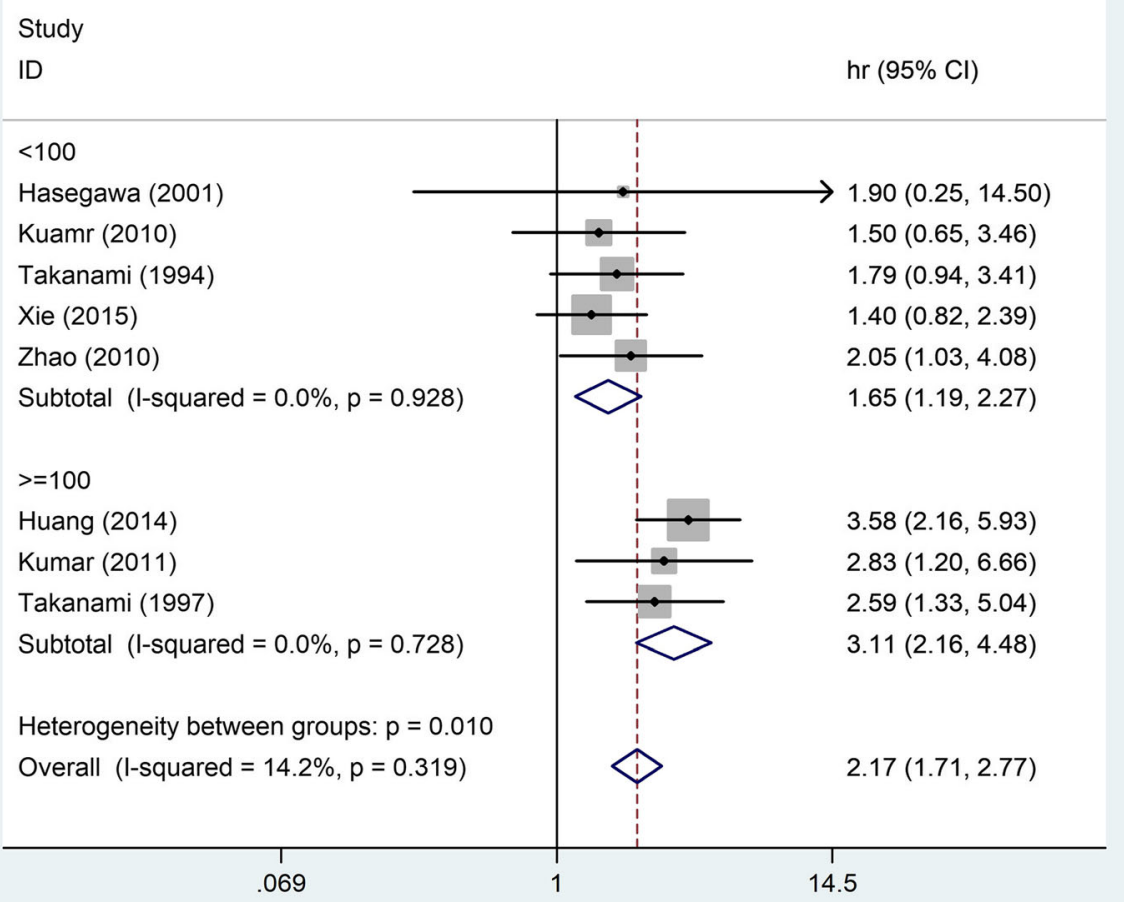

Fig. 5 Pooled HRs for assessing of the association between TGF- $\beta$ expression and quantity of sample in studies. HR Hazard ratio, Cl Confidence interval, ES Effect size

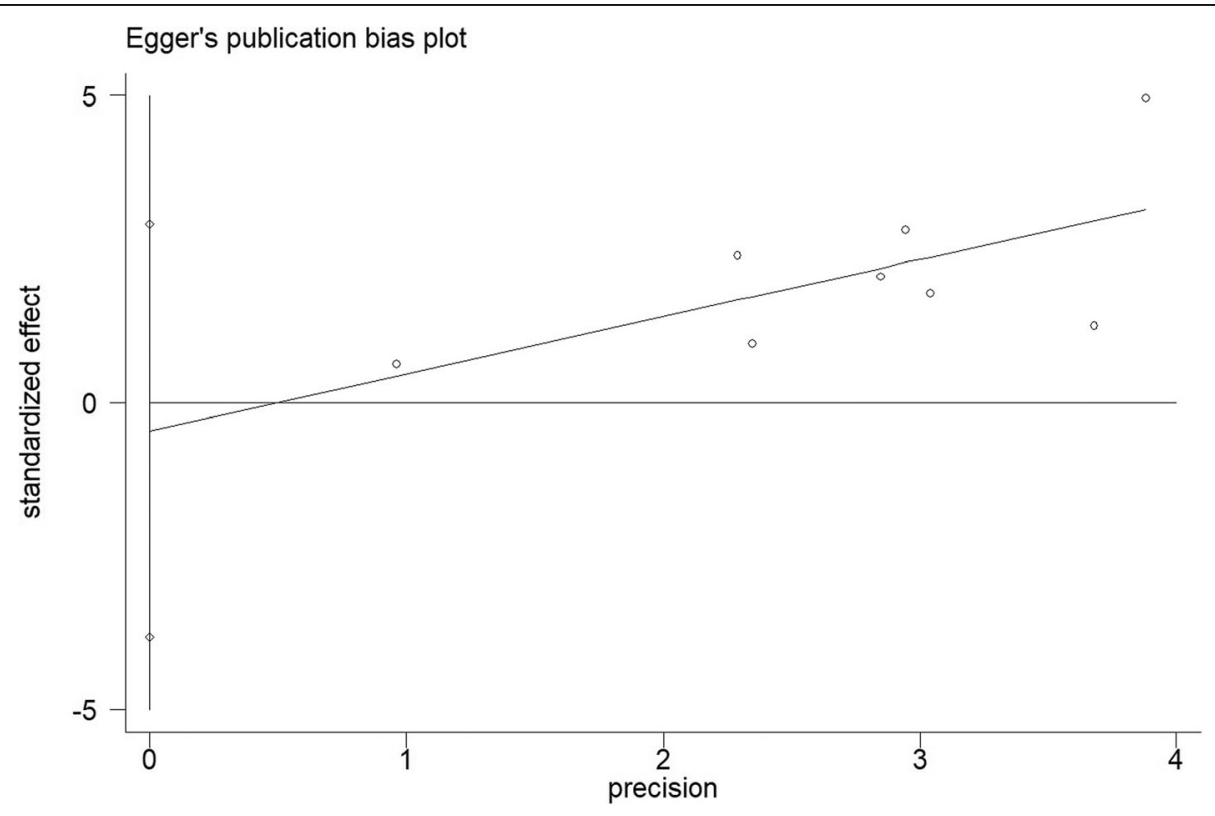

Fig. 6 Egger's publication bias plot 
Begg's funnel plot with pseudo $95 \%$ confidence limits

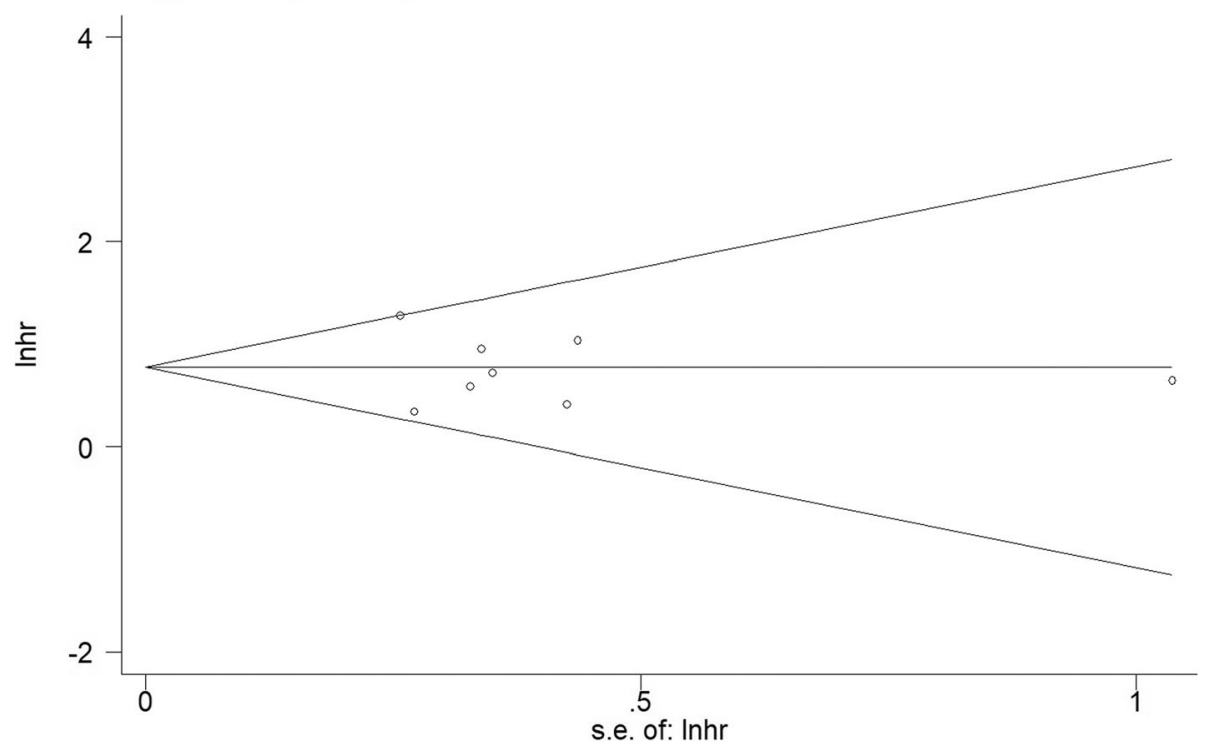

Fig. 7 Funnel plots of publication bias on the correlation between TGF- $\beta$ expression and overall survival

levels and the disease status in lung cancer patients without examining the prognosis. Analyzing the prognostic value of TGF- $\beta$ specifically in lung cancer using metaanalysis in our study, we further performed the subgroup analysis including the assessment of the association between TGF- $\beta$ expression and pathology, treatment or the quantity of sample in all studies. High expression of TGF$\beta$ was associated with worse survival in patients with NSCLC can be concluded from our results.

There are several limitations in this meta-analysis. Firstly, the number of studies included and the simple scale were relatively small. Secondly, some of the HRs with 95\% CI was not directly extracted from the studies and some errors may have occurred during the rebuilding of HR calculated via Kaplan-Meier survival curves. Thirdly, all of the populations included in the eight studies evaluated in our analysis were Asian and there might be an ethnic bias. Fourthly, all included studies used ELISA to detect the TGF- $\beta$; there may be differences in reagents, operation steps and results, which may give rise to bias. The results of subgroup analysis revealed that sample size, specimen type, source of HR and survival analysis mode might contribute to the heterogeneity.

\section{Conclusions}

In conclusion, our meta-analysis showed that high expression of TGF-beta could significantly predict poor prognosis in NSCLC patients. The small numbers of studies examined may influence the validity of this conclusion. Therefore, the results of our meta-analysis should be better confirmed with additional relevant research in the future using updated analyses.

\section{Abbreviations}

ADC: Adenocarcinoma; Cl: Confidence interval; CNKI: China National Knowledge Infrastructure; CT: Computed tomography; ELISA: Enzyme-linked immuno sorbent assay; EMT: Epithelial to mesenchymal transition; FFPE: Formalin-Fixed and Parrffin-Embedded; HR: Hazard ratio; NE: Negative expression; NOS: Newcastle-Ottawa Scale; NSCLC: Non-small cell lung cancer; PE: Postive expression; ROS: Review observational study; RT: Radiation therapy; SCC: Squamous cell carcinoma; TGF- $\beta$ : Transforming growth factor beta; TNM: Tumor, Lymph Node, Metastasis

\section{Acknowledgements}

We greatly appreciate the assistance of the staff of the Department of Thoracic Surgery, West-China Hospital, Sichuan University, and thank them for their efforts.

\section{Authors' contributions}

$J \mathrm{~L}$ and $\mathrm{CS}$ were involved in drafting the manuscript. $\mathrm{XW}, \mathrm{YL}, \mathrm{KZ}$ and $\mathrm{PL}$ made contributions to the concepts, acquisition and analysis of the data. LL was involved in acquisition of data and preparing the Figs. GC designed and revised the manuscript. All authors have read and approved the final manuscript.

\section{Funding}

Not applicable.

\section{Availability of data and materials}

All data for this study are publicly available and are ready for the public to download at no cost from the official websites of the PubMed, EMBASE, the Web of Science and China National Knowledge Infrastructure. There is no need to have the formal permission to use data for this study. The sources and data robustness have been described in the section of "Methods".

\section{Ethics approval and consent to participate}

All the data supporting our findings in this paper were freely downloaded from the PubMed, EMBASE, the Web of Science and China National Knowledge Infrastructure websites. No ethical approval or written informed consent for participation was required.

Consent for publication

Not applicable. 


\section{Competing interests}

The authors declare that they have no competing interests.

Received: 16 September 2018 Accepted: 9 July 2019

Published online: 15 July 2019

\section{References}

1. Emprou C. SNAI2 and TWIST1 in lymph node progression in early stages of NSCLC patients. Sci Rep. 2018.

2. Dvornikov D, Schneider MA, Ohse S, Szczygiel M, Titkova I, Rosenblatt M, Muley $T$, Warth A, Herth FJ, Dienemann $\mathrm{H}$ et al: Expression ratio of the TGF beta-inducible gene MYO10 is prognostic for overall survival of squamous cell lung cancer patients and predicts chemotherapy response. 2018, 8(1):9517.

3. Deng G, Chen L, Zhang Y, Fan S, Li W, Lu J, Chen X. Fucosyltransferase 2 induced epithelial-mesenchymal transition via TGF-beta/Smad signaling pathway in lung adenocarcinaoma. Exp Cell Res. 2018.

4. Xie M, He C, Wei S: [Relationship between Expression of TGF-beta1, Smad2, Smad4 and Prognosis of Patients with Resected Non-small Cell Lung Cancer]. Zhong guo fei ai za zhi = Chinese journal of lung cancer 2015, 18(9):543-548

5. Zhang S, Che DH, Yang F, Chi CL, Meng HX, Shen J, Qi L, Liu F, Lv LY, Li Y, et al. Tumor-associated macrophages promote tumor metastasis via the TGF-beta/SOX9 axis in non-small cell lung cancer. Oncotarget. 2017:8(59): 99801-15

6. Vazquez PF, Carlini MJ, Daroqui MC, Colombo L, Dalurzo ML, Smith DE, Grasselli J, Pallotta MG, Ehrlich M. Bal de kier Joffe ED et al: TGF-beta specifically enhances the metastatic attributes of murine lung adenocarcinoma: implications for human non-small cell lung cancer. Clinical \& experimental metastasis. 2013;30(8):993-1007.

7. Okayama A, Miyagi Y, Oshita F, Ito H, Nakayama H, Nishi M, Kurata Y, Kimura $Y$, Ryo A, Hirano H. Identification of tyrosine-phosphorylated proteins upregulated during epithelial-mesenchymal transition induced with TGFbeta. J Proteome Res. 2015;14(10):4127-36.

8. Takanami I, Tanaka F, Hashizume T, Kikuchi K, Yamamoto Y, Yamamoto T, Kodaira S. Transforming growth factor-beta isoforms expressions in pulmonary adenocarcinomas as prognostic markers: an immunohistological study of one hundred and twenty patients. Oncology. 1997;54(2):122-8.

9. Sanjeev Mariathasan, Shannon J. Turley, Dorothee Nickles et al. TGF $\beta$ attenuates tumour response to PD-L1 blockade by contributing to exclusion of T cells. Nature, Published online: 14 February 2018, doi:https://doi.org/1 0.1038 /nature25501

10. Peng $L$, Yuan $X Q$, et al. High TGF- $\beta 1$ expression predicts poor disease prognosis in hepatocellular carcinoma patients. Oncotarget. 2017;8(21): 34387-97. https://doi.org/10.18632/oncotarget.16166.

11. Takanami I, Imamura T, Hashizume T, Kikuchi K, Yamamoto Y, Kodaira S. Transforming growth factor beta 1 as a prognostic factor in pulmonary adenocarcinoma. J Clin Pathol. 1994:47(12):1098-100.

12. Kumar S, Guleria R, Mohan A, Singh V, Bharti AC, Das BC. Efficacy of plasma TGF-beta beta 1 level in predicting therapeutic efficacy and prognosis in patients with advanced non-small cell lung Cancer. Cancer Investig. 2011; 29(3):202-7.

13. Huang AL, Liu SG, Qi WJ, Zhao YF, Li YM, Lei B, Sheng WJ, Shen H. TGF-beta 1 protein expression in non-small cell lung cancers is correlated with prognosis. Asian Pac J Cancer Prev. 2014;15(19):8143-7.

14. Gao Y, Wang Y, Sun L, Meng Q, Cai L, Dong X. Expression of TGFbeta-1 and EHD1 correlated with survival of non-small cell lung cancer. Tumour biology : the journal of the International Society for Oncodevelopmental Biology and Medicine. 2014:35(9):9371-80.

15. Hasegawa Y, Takanashi S, Kanehira Y, Tsushima T, Imai T, Okumura K. Transforming growth factor-beta1 level correlates with angiogenesis, tumor progression, and prognosis in patients with nonsmall cell lung carcinoma. Cancer. 2001;91(5):964-71.

16. Zhao LJ, Ji W, Zhang L, Ou GF, Feng QF, Zhou ZM, Lei MF, Yang WZ, Wang $\mathrm{LH}$. Changes of circulating transforming growth factor-beta 1 level during radiation therapy are correlated with the prognosis of locally advanced non-small cell lung Cancer. J Thorac Oncol. 2010;5(4):521-5.

17. Kumar S, Guleria R, Mohan A, Singh V, Ali A, Bharti AC, Das BC. Utility of plasma tumour necrosis factor-alpha and transforming growth factor-beta 1 as predictors of survival and treatment outcome in advanced non-small cell lung carcinoma. Biomarkers. 2010;15(5):446-53.
18. Liu HL, Zhang MS, Xu SS, Zhang J, Zou J, Yang CC, Zhang Y, Gong C, Kai YZ, Li Y. HOXC8 promotes proliferation and migration through transcriptional upregulation of TGF beta 1 in non-small cell lung cancer. Oncogenesis. 2018;7.

19. Liu SG, Yuan SH, Wu HY, Liu J, Huang CS. The clinical research of serum VEGF, TGF-beta 1, and Endostatin in non-small cell lung Cancer. Cell Biochem Biophys. 2015;72(1):165-9.

20. Ye YY, Liu S, Wu CY, Sun ZP. TGF beta modulates inflammatory cytokines and growth factors to create premetastatic microenvironment and stimulate lung metastasis. J Mol Histol. 2015;46(4-5):365-75.

21. Xiong Y, Zhang J, Shi LZ, Ning YY, Zhu Y, Chen S, Yang M, Chen JY, Zhou GW, Li Q. NOGO-B promotes EMT in lung fibrosis via MMP14 mediates free TGF-beta1 formation. Oncotarget. 2017;8(41):71024-37.

22. Yang L, Zhang F, Wang X, Tsai Y, Chuang KH, Keng PC, Lee SO, Chen Y. A FASN-TGF-beta1-FASN regulatory loop contributes to high EMT/metastatic potential of cisplatin-resistant non-small cell lung cancer. Oncotarget. 2016; 7(34):55543-54.

23. Yang $H$, Zhan L, Yang T, Wang L, Li C, Zhao J, Lei Z, Li X, Zhang HT. Ski prevents TGF-beta-induced EMT and cell invasion by repressing SMAD-dependent signaling in non-small cell lung cancer. Oncol Rep. 2015;34(1):87-94.

24. Khan GJ, Gao Y, Gu M, Wang L, Khan S, Naeem F, Semukunzi H, Roy D, Yuan S, Sun L. TGF-beta1 causes EMT by regulating $\mathrm{N}$-acetyl Glucosaminyl transferases via downregulation of non muscle myosin IIA through JNK/P38/PI3K pathway in lung Cancer. Curr Cancer Drug Targets. 2018;18(2):209-19.

25. Elmansuri AZ, Tanino MA, Mahabir R, Wang L, Kimura T, Nishihara H, Kinoshita I, Dosaka-Akita H, Tsuda M, Tanaka S. Novel signaling collaboration between TGF-beta and adaptor protein Crk facilitates EMT in human lung cancer. Oncotarget. 2016;7(19):27094-107.

26. Xu Y, Lou Z, Lee SH. Arctigenin represses TGF-beta-induced epithelial mesenchymal transition in human lung cancer cells. Biochem Biophys Res Commun. 2017:493(2):934-9.

27. Wei Y, Li D, Wang D, Qiu T, Liu K. Evaluation of microRNA-203 in bone metastasis of patients with non-small cell lung cancer through TGF-beta/ SMAD2 expression. Oncol Rep. 2017.

28. Wang $H$, Wu Q, Zhang $Y$, Zhang HN, Wang YB, Wang W. TGF-beta1-induced epithelial-mesenchymal transition in lung cancer cells involves upregulation of miR-9 and downregulation of its target. E-cadherin Cellular \& molecular biology letters. 2017;22:22

\section{Publisher's Note}

Springer Nature remains neutral with regard to jurisdictional claims in published maps and institutional affiliations.

Ready to submit your research? Choose BMC and benefit from:

- fast, convenient online submission

- thorough peer review by experienced researchers in your field

- rapid publication on acceptance

- support for research data, including large and complex data types

- gold Open Access which fosters wider collaboration and increased citations

- maximum visibility for your research: over $100 \mathrm{M}$ website views per year

At $\mathrm{BMC}$, research is always in progress.

Learn more biomedcentral.com/submission 